\title{
Correction to: Cost-effectiveness of orbital atherectomy compared to rotational atherectomy in treating patients with severely calcified coronary artery lesions in Japan
}

\author{
Jan B. Pietzsch ${ }^{1} \cdot$ Benjamin P. Geisler $^{1,2} \cdot$ Fumiaki Ikeno $^{3}$
}

Published online: 27 October 2017

(C) The Author(s) 2017. This article is an open access publication

\section{Correction to: Cardiovasc Interv and Ther}

\section{DOI 10.1007/s12928-017-0488-3}

In the original publication of this article, in Abstract the 1 -year mortality of OAS should be stated as 4.7 and not $5.5 \%$.

Open Access This article is distributed under the terms of the Creative Commons Attribution 4.0 International License (http://creativecommons.org/licenses/by/4.0/), which permits unrestricted use, distribution, and reproduction in any medium, provided you give appropriate credit to the original author(s) and the source, provide a link to the Creative Commons license, and indicate if changes were made.

The online version of the original article can be found under doi:10.1007/s12928-017-0488-3.

Fumiaki Ikeno

fikeno@stanford.edu

1 Wing Tech Inc., Menlo Park, CA, USA

2 Department of Medicine, Massachusetts General

Hospital/Harvard Medical School, Boston, MA, USA

3 Division of Cardiovascular Medicine, Stanford University

School of Medicine, 300 Pasteur Drive, FALK CVRB

CV-007, Stanford, CA 94305, USA 